\title{
The Influence of the Rotational Speed of the Polymer SU8 on the Thickness of the Waveguide Layer
}

\author{
K. Gut*, T. Pustelny and D. Nabageo \\ Department of Optoelectronics, Silesian University of Technology \\ Krzywoustego 2, 44-100 Gliwice, Poland
}

\begin{abstract}
The paper presents results of investigations concerning the measurement of the refractive index and thickness of planar waveguide structures, obtained by the photopolymerization of polymer SU8. Sodium-calcium glass was used as the substrate. As the knowledge of the quoted parameters is from the viewpoint of the structure of various types of optical sensors of crucial importance, the way of their determination has been presented. The paper deals also with the method of constructing planar polymer waveguides, taking into account problems connected with their adhesion to glass substrates.
\end{abstract}

PACS numbers: 42.25.Hz, 42.25.-p, 42.70.-a, 42.82.-m, 42.82.Et, 68.35.Ct

\section{Introduction}

For the purpose of constructing optical planar sensors various techniques are applied, e.g. ion exchange, plasma-enhanced chemical vapour deposition (PECVD) and spin coating in the case of SU8-polymer waveguides [1-11].

SU8 is a polymer based on epoxy resin, developed in 1989 by IBM. Thanks to its properties it is now one of the most attractive materials used in the optical planar technology. SU8 is rather cheap and displays a high thermal and chemical stability as well as good resistance to mechanical damages and an unusual transparency [6]. The wide range of products ready for use, offered by the manufacturers of the SU8 (MicroChem and Gersteltec Sari), in the course of one technological process layers can be obtained with a thickness of $1 \mu \mathrm{m}$ up to $2 \mathrm{~mm}$ [12].

Such good properties of polymer SU8 are due to its unique structure. The chief component is epoxy resin, called $\mathrm{EPON}^{\circledR}$, consisting of SU monomers, and responsible for its mechanical properties and adhesion to the substrate. Another also very important component is the photoinitiatis, viz. Lewis acid, responsible for the initiation of the cross-linking, in the course of which an epoxy ring is opened [12]. The last component is a solvent, which is indispensable for warranting adequate viscosity of the mixture.

So far SU8 has been applied mainly in the technologies micro-electro-mechanical system (MEMS) and micro-opto-electromechanical-systems (MOEMS), being a highly resistant and very sensitive photoresist processes involving selective plasma digestion, but also in photolithography [13]. Because of its very good optical properties [14] it is utilized in the production of optical sensors operating in the interferometer system $[13,15]$.

\section{Fabrication}

For the purpose of investigations a series of planar waveguide structures was prepared for the SU8 polymer of varying thicknesses. As a substrate soda-lime glass plates were used, previously washed and rinsed in nitric acid, acetic acid and ammonia liquor. The polymer SU8 is characterized by a weak adhesion to glass substrates [15]; therefore, in order to avoid damages of the structure in the course of depositing the polymer the entire procedure of washing was accomplished in a laminar cell with air filtration, holding it for 5 min at a temperature of $130^{\circ} \mathrm{C}$. Upon the substrate SU8 was deposited by spin coating in a centrifuge from the firm Rein Raum Technik Lanz, specially adapted for this purpose. The proper amount of SU8 was batched by means of an automatic feeder with its nozzle directed towards the immovable substrate mounted in the centrifuge. The thickness of the layers depended on the velocity of gyration of the centrifuge.

In order to improve the homogeneity of the coating, each plate was after the deposition of SU8 cooled down for 5 min to room temperature (relax time). Next each structure was subjected to initial soft baking on a hot plate provided with a micro-processing programmer. At this stage the controlling of the temperature is of crucial importance for the whole process, and just therefore its precise measurement is indispensable.

Each structure, irrespective of the thickness of the waveguide SU8 layer, was preheated from room temperature to $65^{\circ} \mathrm{C}$ with a surplus of $2{ }^{\circ} \mathrm{C}[15]$, after which the temperature of $65^{\circ} \mathrm{C}$ was maintained for $10 \mathrm{~min}$. The following step was the heating up from $65^{\circ} \mathrm{C}$ to $95^{\circ} \mathrm{C}$ with a surplus of $2^{\circ} \mathrm{C} / \mathrm{min}$, whose latest temperature was maintained for $60 \mathrm{~min}$.

* corresponding author; e-mail: kgut@polsl.pl 
Technological conditions of deposition of SU8 layers.

TABLE I

\begin{tabular}{|c|c|c|c|c|c|c|}
\hline $\begin{array}{c}\text { Spin } \\
\text { speed [rpm] }\end{array}$ & Pre-baking & $\begin{array}{c}\text { Relax. } \\
\text { time [min] }\end{array}$ & $\begin{array}{c}\text { Exposure } \\
\text { time }[\mathrm{s}]\end{array}$ & $\begin{array}{l}\text { UV dose } \\
{\left[\mathrm{mJ} / \mathrm{cm}^{2}\right]}\end{array}$ & $\begin{array}{c}\text { Post-exposure } \\
\text { baking }\end{array}$ & $\begin{array}{c}\text { Developing } \\
\text { time }[\mathrm{s}]\end{array}$ \\
\hline 2000 & $\begin{array}{c}25^{\circ} \mathrm{C}-65^{\circ} \mathrm{C} / 20 \mathrm{~min} \\
65^{\circ} \mathrm{C} / 6 \mathrm{~min}, \\
65^{\circ} \mathrm{C}-95^{\circ} \mathrm{C} / 15 \mathrm{~min}, \\
95^{\circ} \mathrm{C}-40 \mathrm{~min}\end{array}$ & 5 & 42 & 235 & $\begin{array}{c}25^{\circ} \mathrm{C}-65^{\circ} \mathrm{C} / 20 \mathrm{~min} \\
65^{\circ} \mathrm{C} / 6 \mathrm{~min}, \\
65^{\circ} \mathrm{C}-95^{\circ} \mathrm{C} / 15 \mathrm{~min}, \\
95^{\circ} \mathrm{C}-22 \mathrm{~min}\end{array}$ & 35 \\
\hline 3000 & $\begin{array}{c}25^{\circ} \mathrm{C}-65^{\circ} \mathrm{C} / 20 \mathrm{~min} \\
65^{\circ} \mathrm{C} / 6 \mathrm{~min}, \\
65^{\circ} \mathrm{C}-95^{\circ} \mathrm{C} / 15 \mathrm{~min}, \\
95^{\circ} \mathrm{C}-40 \mathrm{~min}\end{array}$ & 5 & 36 & 202 & $\begin{array}{c}25^{\circ} \mathrm{C}-65^{\circ} \mathrm{C} / 20 \mathrm{~min} \\
65^{\circ} \mathrm{C} / 6 \mathrm{~min}, \\
65^{\circ} \mathrm{C}-95^{\circ} \mathrm{C} / 15 \mathrm{~min}, \\
95^{\circ} \mathrm{C}-22 \mathrm{~min}\end{array}$ & 30 \\
\hline 4000 & $\begin{array}{c}25^{\circ} \mathrm{C}-65^{\circ} \mathrm{C} / 20 \mathrm{~min} \\
65^{\circ} \mathrm{C} / 6 \mathrm{~min}, \\
65^{\circ} \mathrm{C}-95^{\circ} \mathrm{C} / 15 \mathrm{~min}, \\
95^{\circ} \mathrm{C}-40 \mathrm{~min}\end{array}$ & 5 & 32 & 180 & $\begin{array}{c}25^{\circ} \mathrm{C}-65^{\circ} \mathrm{C} / 20 \mathrm{~min} \\
65^{\circ} \mathrm{C} / 6 \mathrm{~min}, \\
65^{\circ} \mathrm{C}-95^{\circ} \mathrm{C} / 15 \mathrm{~min}, \\
95^{\circ} \mathrm{C}-22 \mathrm{~min}\end{array}$ & 27 \\
\hline 5000 & $\begin{array}{c}25^{\circ} \mathrm{C}-65^{\circ} \mathrm{C} / 20 \mathrm{~min} \\
65^{\circ} \mathrm{C} / 6 \mathrm{~min}, \\
65^{\circ} \mathrm{C}-95^{\circ} \mathrm{C} / 15 \mathrm{~min}, \\
95^{\circ} \mathrm{C}-40 \mathrm{~min}\end{array}$ & 5 & 28 & 157 & $\begin{array}{c}25^{\circ} \mathrm{C}-65^{\circ} \mathrm{C} / 20 \mathrm{~min} \\
65^{\circ} \mathrm{C} / 6 \mathrm{~min}, \\
65^{\circ} \mathrm{C}-95^{\circ} \mathrm{C} / 15 \mathrm{~min}, \\
95^{\circ} \mathrm{C}-22 \mathrm{~min}\end{array}$ & 25 \\
\hline
\end{tabular}

After the structure had been cooled down to about $30^{\circ} \mathrm{C}$ its exposure was started. For this purpose an irradiator MJB3 produced by the firm Karl Suss was used. The batching of UV radiation by means of a mercury discharge lamp (OSRAM HBO $250 \mathrm{~W}$ ) was adjusted individually for each thickness of the SU8 layer. The parameters of irradiation have been gathered in Table I. The irradiation was followed by post-exposure baking, similarly as in the case of preliminary soft baking.

The final stage of generation was the development of the structure by means of the developer PGME [15]. The time of the development can also be gathered from Table I. After their development the structure was washed with isopropanol and dried at room temperature.

\section{Determination of the refractive index}

In order to determine the refractive index of a step-index waveguide structure, based on the polymer SU8, the numerical method was applied, requiring the determination of the effective refraction indices for each observed mode. By means of mode spectroscopy a set of effective refractive indices was determined for the wavelength $633 \mathrm{~nm}$, concerning the planar waveguides. An exemplary mode spectrum recorded for the planar waveguide SU8 can be seen in Fig. 1.

The synchronic angles were measured for the polymer waveguides obtained at rotational speeds of 2000, 3000 and $5000 \mathrm{rpm}$. Basing on the measured synchronic angle the effective refractive indices were calculated for all modes of each polarization. In the case of waveguides in which not more than 2 modes could be observed, the denotations 0 and 1 were applied successively, i.e. mode of the zero and first order. The effective refractive indices are connected with the refractive index resulting from the dispersive Eq. (1) [16]:

$$
k W\left(n^{2}-N_{m}^{2}\right)^{1 / 2}=\Psi_{m}\left(n, N_{m}\right),
$$

where $k$ - wave number, $W$ - thickness of the wave-

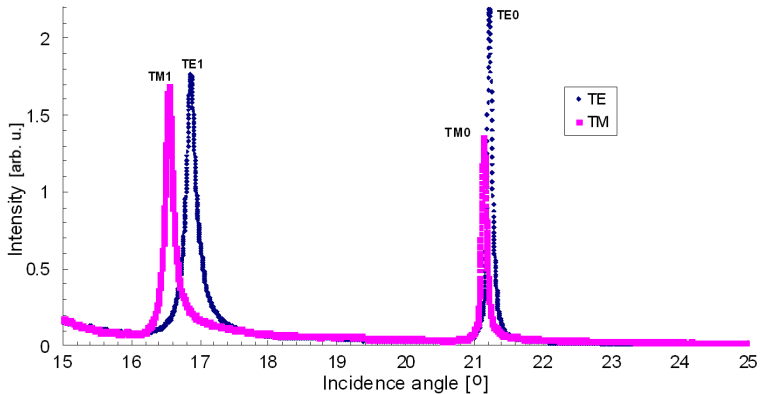

Fig. 1. Mode spectrum of the polymer waveguide SU8, obtained at rotational speeds of $2000 \mathrm{rpm}$.

guide layer, $n$ - refractive index of the waveguide layer, $N_{m}$ - effective refractive index of the $m$-th mode.

The expansion of the characteristic function $\Psi_{m}\left(n, N_{m}\right)$ can be expressed by the relation (2) [16]:

$$
\Psi_{m}\left(n, N_{m}\right)=m \pi+\phi_{0}\left(n, N_{m}\right)+\phi_{2}\left(n, N_{m}\right),
$$

where $m$ - number of the mode, $\phi_{j}$ - function $(j=0$ - for the substrate, $j=2$ - for the cover).

The functions $\phi_{0}\left(n, N_{m}\right)$ and $\phi_{2}\left(n, N_{m}\right)$ according to $(3)$ :

$$
\phi_{j}\left(n, N_{m}\right)=\arctan \left[\left(\frac{n}{n_{j}}\right)^{2 \rho}\left(\frac{N_{m}^{2}-n_{j}^{2}}{n^{2}-N_{m}^{2}}\right)\right]^{1 / 2},
$$

where $n_{j}$ - refractive index of the substrate at $j=0$ and the cover at $j=2, \rho$ - identifier of the polarization ( $\rho=0$ for TE and $\rho=1$ for TM).

Substituting the previously determined effective refractive indices for the mode of the zero order $N_{0}$ and first order $N_{1}$ into Eqs. (1), (2) and (3), and eliminating the index $k W$, we get the relation for the refractive index (4) $[16]$ : 


$$
n^{2}=F\left(n^{2}\right),
$$

where

$$
F\left(n^{2}\right)=\frac{N_{0}^{2} \Psi_{1}^{2}-N_{1}^{2} \Psi_{0}^{2}}{\Psi_{1}^{2}-\Psi_{0}^{2}},
$$

TABLE II

Results of measurements of the refractive index of waveguide layers SU8 at $\lambda=633 \mathrm{~nm}$.

\begin{tabular}{c|c|c|c}
\hline \hline \multicolumn{5}{c}{ Spin speed 2000 [rpm] } \\
\hline Mode & $\begin{array}{c}\text { Synchronic angle } \\
\phi_{m}\end{array}$ & $N_{\text {eff }}$ & $\begin{array}{c}\text { Numerically determined } \\
\text { refractive index } n\end{array}$ \\
\hline $\mathrm{TE}_{0}$ & $21.22(4)$ & $1.5781(2)$ & \\
$\mathrm{TE}_{1}$ & $16.86(4)$ & $1.5420(2)$ & $1.592(2)$ \\
$\mathrm{TM}_{0}$ & $21.14(4)$ & $1.5774(2)$ & \\
$\mathrm{TM}_{1}$ & $16.54(4)$ & $1.5393(2)$ & $1.597(3)$ \\
\hline \multicolumn{5}{c}{ Spin speed 3000 [rpm] } \\
\hline $\mathrm{TE}_{0}$ & $21.54(4)$ & $1.5806(2)$ & \\
$\mathrm{TE}_{1}$ & $17.01(4)$ & $1.5433(2)$ & \\
$\mathrm{TM}_{0}$ & $21.37(4)$ & $1.5793(2)$ & $1.594(1)$ \\
$\mathrm{TM}_{1}$ & $16.62(4)$ & $1.5399(2)$ & \\
\hline \multicolumn{5}{c}{ Spin speed 5000 [rpm] } \\
$\mathrm{TE}_{0}$ & $21.17(4)$ & $1.5777(2)$ & \\
$\mathrm{TE}_{1}$ & $15.54(4)$ & $1.5305(2)$ & \\
$\mathrm{TM}_{0}$ & $21.08(4)$ & $1.5770(2)$ & \\
$\mathrm{TM}_{1}$ & $15.20(4)$ & $1.5275(2)$ &
\end{tabular}

Due to the form of Eq. (5), the refractive index can be calculated, applying the iterative method, presented in $[16]$.

The considerations dealt with above are correct in the case of step-index waveguides. Having at one's disposal two values of the refractive index for each polarization, the refractive index of the waveguide layer can be determined for every arrangement of these values. The results of calculations of the values of the refractive index of waveguide layers have been gathered in Table II.

\section{Determination of the thickness of the waveguide layer}

Any change of the thickness of the waveguide layer affects directly the number of waveguide modes propagating in it. Information about the thickness of the waveguide permits to assess what number of modes (at the selected wavelength) will propagate in the given structure and is of essential importance with respect to arrangement of the system in which it is to be applied.

The value of the refractive index obtained by means of spectroscopy permits in many cases to determine mathematically the thickness of the waveguide layer [16]. Another method is the measurement of the thickness by means of special devices.

By performing Eq. (1), we obtain easily a formula, by means of which the thickness of the waveguide layer can be calculated (6) [16]:

$$
W=\frac{\Psi_{m}\left(n, N_{m}\right)}{k\left(n^{2}-N_{m}^{2}\right)^{1 / 2}} .
$$

For every combination of mode pairs the value of the
TABLE III

Results of calculation concerning the thickness of waveguide layer SU8.

\begin{tabular}{c|c|c|c}
\hline \hline \multicolumn{4}{c}{ Spin speed $2000[\mathrm{rpm}]$} \\
\hline Mode & $\begin{array}{c}\text { Synchronic angle } \\
\phi_{m}\end{array}$ & $N_{\text {eff }}$ & $\begin{array}{c}\text { Calculated thickness } \\
W[\mu \mathrm{m}]\end{array}$ \\
\hline $\mathrm{TE}_{0}$ & $21.22(4)$ & $1.5781(2)$ & $1.38(2)$ \\
$\mathrm{TE}_{1}$ & $16.86(4)$ & $1.5420(2)$ & \\
$\mathrm{TM}_{0}$ & $21.14(4)$ & $1.5774(2)$ & $1.29(6)$ \\
$\mathrm{TM}_{1}$ & $16.54(4)$ & $1.5393(2)$ & \\
\hline \multicolumn{5}{|c}{ Spin speed 3000 [rpm] } \\
\hline $\mathrm{TE}_{0}$ & $21.54(4)$ & $1.5806(2)$ & \\
$\mathrm{TE}_{1}$ & $17.01(4)$ & $1.5433(2)$ & $1.20(3)$ \\
$\mathrm{TM}_{0}$ & $21.37(4)$ & $1.5793(2)$ & \\
$\mathrm{TM}_{1}$ & $16.62(4)$ & $1.5399(2)$ & \\
\hline \multicolumn{5}{c}{ Spin speed $5000[\mathrm{rpm}]$} \\
$\mathrm{TE}_{0}$ & $21.17(4)$ & $1.5777(2)$ & \\
$\mathrm{TE}_{1}$ & $15.54(4)$ & $1.5305(2)$ & \\
$\mathrm{TM}_{0}$ & $21.08(4)$ & $1.5770(2)$ & \\
$\mathrm{TM}_{1}$ & $15.20(4)$ & $1.5275(2)$ &
\end{tabular}

thickness was determined basing on the previously calculated refractive index.

Table III contains the results of calculations of the thickness of waveguide layer consisting of SU8. The calculations were based on data resulting from the analysis of mode spectra concerning the respective waveguide and on the previously calculated value of the refractive index. The obtained results confirm profilometrical measurements.

\section{Conclusion}

Investigations concerning the achievement of planar waveguides on glass substrates indicate that there are problems connected with the adhesion of SU8 to the substrates. The adhesion can be improved by adequate rinsing and soaking previous to the deposition of the polymer. For the investigations waveguides were chosen which had been obtained at rotational speeds of 2000 , 3000 and $5000 \mathrm{rpm}$, in which two modes of a TE polarization and two of a TM polarization were propagated. The aim of the investigations was to determine the effective refractive indices and to calculate the value of the refractive index and thickness of the waveguide layer. The obtained results prove the correctness of the assumptions, which had been made when the parameters of the technological process were being decided. The values of the refractive index concerning various thicknesses of the waveguides were similar. The results of profilometrical measurements coincided with the later on calculated of the thickness of polymeric waveguides.

\section{Acknowledgments}

The work was sponsored by the State Committee for Scientific Research (NCBiR) within the grant N R01 034 $06 / 2009$. 


\section{References}

[1] T. Pustelny, Physical and Technical Aspects of Optoelectronic Sensors, SUT University of Technology, Gliwice 2005, p. 86.

[2] A. Sabac, C. Gorecki, M. Jozwik, L. Nieradko, C. Meunier, K. Gut, J. Eur. Op. Soc.-Rapid 2, 07026 (2007).

[3] K. Gut, Acta Phys. Pol. A 114, A-121 (2008).

[4] K. Gut, J. Phys. IV 137, 91 (2006).

[5] K. Gut, J. Phys. IV 129, 109 (2005).

[6] K. Gut, K. Nowak, Eur. Phys. J.-Spec. Top. 154, 89 (2008).

[7] M. Błahut, D. Kasprzak, Acta Phys. Pol. A 116, 257 (2009).

[8] M. Błahut, D. Kasprzak, M. Sujewicz, Acta Phys. Pol. A 116, 264 (2009).

[9] M. Błahut, K. Bazan, Acta Phys. Pol. A 116, 257 (2009).
[10] M. Błahut, D. Kasprzak, Opt. Appl. 33, 613 (2003).

[11] P. Struk, T. Pustelny, K. Gut, K. Gołaszewska, E. Kamińska, M. Ekielski, I. Pasternak, E. Łusakowska, A. Piotrowska, Acta Phys. Pol. A 116, 414 (2009).

[12] L. Akesso, SU8 Technical Datasheet, Gersteltec Sarl, 2005.

[13] M. Bednorz, M. Urbańczyk, T. Pustelny, A. Piotrowska, E. Papis, Z. Sidor, E. Kamińska, Mol. Quant. Acoust. 27, 31 (2006).

[14] K. Gut, D. Nabaglo, Acta Phys. Pol. A 116, 307 (2009).

[15] B. Beche, N. Pelletier, E. Gaviot, J. Zyss, Opt. Commun. 230, 91 (2004).

[16] R. Urlich, R. Torge, Appl. Opt. 12, 2901 (1973). 